\title{
Erratum
}

\section{Synthesis and Absolute Configuration of the 7-Phenylhepta-4,6-diyne-1,2-diol Isolated from Bidens pilosa}

Shan Cui, Yang Zou, Yikang Wu,* Po Gao* Synthesis 2011, 2131.

The configurations for the starting epoxides $(R)-\mathbf{3}$ and $(S)-\mathbf{3}$ were incorrectly drawn; the two structures should be exchanged with one another. The configurations for all intermediates and end products were correct, as further secured by the following optical rotations: for $(R)-4:[\alpha]_{\mathrm{D}}{ }^{23}-16.9\left(c 1.0, \mathrm{CHCl}_{3}\right)\left\{\mathrm{Lit}^{3 \mathrm{a}}[\alpha]_{\mathrm{D}}{ }^{25}-16.4\left(c 1.035, \mathrm{CHCl}_{3}\right)\right\}$; for $(R)-5:[\alpha]_{\mathrm{D}}^{23}-12.4\left(c 0.63, \mathrm{CHCl}_{3}\right)\left\{\right.$ Lit. $\left.^{3 \mathrm{a}}[\alpha]_{\mathrm{D}}{ }^{25}-12.1\left(c 0.62, \mathrm{CHCl}_{3}\right)\right\}$. 